Misstear D.B., Gill L.W. (2012). CFD modelling of fixed photocatalytic inserts for a continuous flow

CPC reactor for water disinfection. Journal of Advanced Oxidation Technology 15(1), 153-162.

\title{
CFD MODELING OF FIXED PHOTOCATALYTIC INSERTS FOR A CONTINUOUS FLOW CPC REACTOR FOR WATER DISINFECTION
}

\begin{abstract}
The design of a suitable fixed photocatalytic support for water disinfection in a compound parabolic collector (CPC) continuous flow reactor receiving solar radiation was researched. Computational fluid dynamics (CFD) was used to simulate the percentage of tracked particles coming into contact with the irradiated surface of different support geometries, cylindrical, conical and consecutive frusta and a spring. The number of particles striking each insert was presumed to give a good representation of the respective disinfection efficiencies of each design, as photocatalysis is effectively a surface phenomenon. It was found that a conical frustum design was more than three times as efficient as a similarly-sized conventional cylindrical insert with regard to this parameter, and arrangements of shorter frusta exhibited even more promising traits. A further regime of laboratory modeling is proposed in order to determine the practical efficiency of the insert designs, which may have important applications in the solar disinfection of drinking water.
\end{abstract}

Key words: photocatalysis, disinfection, CPC, supported catalyst, CFD, solar radiation, titanium dioxide.

\section{Introduction}

The capabilities of titanium dioxide as a photocatalyst for disinfection have been known for the past twenty-five years, since Matsunaga et al. (1) found that E. coli was disinfected more readily under UV light in the presence of $\mathrm{TiO}_{2}$. More recently, attention has turned to optimizing continuous flow reactor design for the use of photocatalysis in practical applications. Continuous flow reactors with Compound Parabolic Collectors (CPCs) are ideally suited to solar photocatalysis and have been used in a number of disinfection studies (2-5) because they have turbulent flow regimes, high optical and quantum efficiency and can make use of both direct and diffuse radiation (6). CPCs designed with a half acceptance angle $\left(\theta_{\mathrm{a}}\right)$ of $90^{\circ}$ can collect all direct and diffuse radiation reaching the collector (6). In this case, the concentration factor of the CPC is 1 (non-imaging system), as

$$
C=\frac{1}{\sin \theta_{a}}
$$

and the entire absorber area of the reactor is homogeneously illuminated (i.e. the sunlight is reflected onto the absorber tubes from all sides), regardless of the irradiance conditions (7).

The majority of research into photocatalytic disinfection has been conducted using titanium dioxide in suspension. The advantages of these systems in comparison to fixed systems include: a lower pressure drop through the reactor; a larger photocatalyst surface area available for adsorption and reaction; and good mass transfer of contaminants from fluid to photocatalyst (8). However, despite its superior efficiency to fixed catalysts, suspended $\mathrm{TiO}_{2}$ requires costly and time-consuming filtration post-treatment and so would be an impractical option for implementing in small-scale water treatment systems located in rural areas with little infrastructure and / or unreliable maintenance. Thus, if an efficient fixed photocatalytic insert could be developed, it would greatly enhance the applicability of solar photocatalysis as an appropriate water treatment process for use in developing countries. Although some authors have investigated alternative methods of photocatalyst removal (9), immobilized photocatalyst reactor systems are becoming ever more popular. Fixed photocatalysts have been proven to be less efficient on a number of occasions against certain microorganisms $(3,10,11)$, but cannot be assumed to be less efficient against all microorganisms, as the reaction mechanisms are 
more complicated and less well understood than for the removal of chemical pollutants (12). Early studies on the efficiency of introducing supported titanium dioxide into photoreactors for disinfection were carried out by Ireland et al. (13), Vidal et al. (14) and McLoughlin et al. (2). An example of a practical application of this type of reactor is the SOLWATER project in Argentina (15), which is designed as an autonomous disinfection system for drinking water in rural areas, which comprises water being recirculated via a pump (powered by PV solar panesl) through tubes containing a supported photocatalyst with CPC collectors. An excellent summary of previous work on reactors in which supported catalyst has been used was presented by Blanco-Galvez et al. (12).

Far more literature is available on the modeling of artificial UV lamp reactors than on the modeling of solar systems $(16,17)$. This is due to the widespread use of ultraviolet disinfection in large-scale water treatment facilities as well as the fact that the more predictable behavior of UV light sources lends itself to more straightforward comparisons with experimental models.

In the research presented in this paper, a variety of insert geometries was modeled in GAMBIT (software for the creation and meshing of geometries for CFD analysis) and examined using FLUENT [Computational Fluid Dynamics (CFD) software for the simulation of flow]. A section of a full-scale CPC reactor system was modeled, each insert was introduced and the flow of $E$. coli was simulated. Previous research was taken into account when sizing the geometries, as presented in Section 2.1. As photocatalytic disinfection relies on close contact between cells and $\mathrm{TiO}_{2}$ particles (18), the number of particles coming into contact with each insert geometry, at a fixed flow rate, was measured. This number was considered to represent successful interactions between bacterial cells and the immobilized catalyst surface, thus giving an indication of the disinfection efficiency of various geometries.

\section{Methods}

\subsection{Geometry parameters}

Malato et al. (6) presented the following equation, which takes into account the refractive index of the medium contained in the CPC:

$$
C_{C P C, \max }=\frac{n a}{2 \pi r}
$$

where $C_{\mathrm{CPC} \text { max }}$ is the maximum concentration factor of a CPC, $r$ is the internal tube radius, $n$ is the refractive index of the liquid passing through the tubes and $a$ is the absorber perimeter. The authors suggested that a practical application stemming from this equation would be the design of fixed photocatalytic inserts. In this case, the above equation could be used to calculate the smallest possible insert diameter whereby no optical losses would be experienced. This theory was put into practice in a subsequent paper (3), in which the authors stated that the optimum optical efficiency for a fixed photocatalytic insert is obtained when the ratio of the inner diameter of the CPC tube $\left(D_{i}\right)$ to the external diameter of the concentric support $\left(d_{e}\right)$ is equal to the refractive index of the fluid $(n)$, or

$$
n=\frac{D_{i}}{d_{e}}
$$

In the case of the full-scale reactor upon which the models were based, the fluid has a refractive index of 1.33 and the internal diameter of the glass tubing is $46 \mathrm{~mm}$. This gives an optimal external diameter of the insert of $34.58 \mathrm{~mm}$. Although this optimizes the concentration ratio, it does not take into account particle residence time. As $d_{e}$ increases, so does the cross-sectional area of the insert, which increases the water velocity around the insert and thus reduces the particle residence time in this region of flow. However, because the cross-sectional area of flow is reduced, particles will be closer (on average) to the insert than if the diameter was smaller. 
As well as light refraction due to the medium, the light absorption effects of the medium can also be investigated using the Beer-Lambert formula. This formula for the light extinction in a well mixed layer of water states that:

$$
I(z)=I_{0} e^{-k_{e} z}
$$

where $I(z)$ is the intensity at a depth $\mathrm{z}$ from the water surface, $I_{0}$ is the intensity at the surface and $k_{e}$ is an extinction coefficient. It should be noted that more accurate modeling of the radiation fields in solar reactors can be carried out using the local volumetric rate of photon absorption (LVPRA) parameter which accounts for absorption and scattering from particles in the water. This is critical when the photocatalyst is used in a slurry form (due to the considerable scattering and absorption from the suspended photocatalyst) and has been used to model such continuous flow solar systems (Brandi et al. 2003; Colina-Márquez et al. 2010). However, the use of such an equation for the system being modeled in this study, with a fixed photocatalyst system at the center of the tubes, was deemed to be too computationally complicated (especially if a numerical solution using the radiative transfer equation (RTE) was attempted), and would also create several other coefficients for which we there would have had no justifiable means to scale without extensive experimentation.

Thus, the ideal shape for the geometries would have:

- A large irradiated surface area, to optimize the number of available contact sites for microorganisms and $\mathrm{TiO}_{2}$

- A small cross sectional area, so that velocities are not too high (and thus bacterial residence times too low) in the vicinity of the insert

- A shape which promotes a degree of turbulence, to ensure E. coli are fully mixed

- A shape that lends itself to easy production for large scale processes

The material for the support needs to be relatively low density, non-reactive and watertight. Previously, materials used have included $\mathrm{TiO}_{2}$ coated glass fiber paper wrapped around polypropylene supports (3).

\subsection{Geometries tested}

\section{Model 1: No Insert}

Initially, a simulation was run with a one metre long section of the glass tube set as the irradiated area under investigation. This simulates the effect of coating the interior of a tube with a transparent sol-gel catalyst in lieu of introducing an insert.

\section{Models 2-5: Cylinders}

The first insert geometry tested was the solid cylinder, conventionally used in photocatalytic reactors $(3,19)$, with a radius of $17.29 \mathrm{~mm}$, as derived from Equation 3. Three other sizes of cylinder were considered, with radii of 10 $\mathrm{mm}, 15 \mathrm{~mm}$ and $20 \mathrm{~mm}$, to investigate whether the idealized optical design would also yield the most favorable disinfection characteristics in comparison to other sizes.

\section{Models 6-9: Conical Frusta}

The solid cylinder has a large irradiated surface area, but because the surface lies in a plane parallel to the flow of water, the number of bacteria coming into contact with it is not optimized. To this end, two conical frustum shapes were conceived as being possible alternatives to cylinders. The radius in the middle of each frustum was kept at $17.29 \mathrm{~mm}$. The first frustum had a minor radius of $16.29 \mathrm{~mm}$ and a major radius of $18.29 \mathrm{~mm}$, and the 
second had a minor radius of $14.29 \mathrm{~mm}$ and a major radius of $20.29 \mathrm{~mm}$. Each frustum was modeled twice, once with the radius increasing in the direction of flow (models $6 \& 8$ ) and once with the radius decreasing in the direction of flow (models $7 \& 9$ ). As an example, the shape of model 7 is displayed in Figure 1 (a).

\section{Models 10-13: Consecutive Frusta}

In order to introduce a greater level of turbulence by further interrupting the cross-sectional area of flow, geometries were created in which 5 frusta were placed end-to-end. This was conducted using the same radii as in models 6-9 and examples of such shapes can be seen in Figures 1 (b) \& (c).

\section{Models 14 \& 15: Spring}

Due to the relatively high cross sectional area associated with a conventional cylindrical insert, the flow surrounding the insert is constricted significantly, increasing the velocity and reducing the residence time in the region of the insert. Therefore, a spring geometry was also created, which had a shape conducive to the creation of turbulence as well as a low cross sectional area in the direction of flow. A tube of radius $2 \mathrm{~mm}$ was constructed along a helix of radius $17.29 \mathrm{~mm}$. Finally, the aforementioned helical shape was wrapped around the cylinder with radius $17.29 \mathrm{~mm}$, to investigate whether the added turbulence increased the number of $E$. coli 'particles' coming into contact with the insert.

\subsection{Creation of geometries in GAMBIT}

A full-scale CPC reactor (AOSOL) was measured in detail and a three-dimensional technical drawing was created in GAMBIT (Figure 2). For the purposes of modeling, to vastly reduce the amount of CPU memory and time required to run simulations, a two-pipe section of the full reactor was simulated. This section included a detailed simulation of a complex bend in the reactor, which is shown in Figure 3, to ensure realistic turbulence profiles would be created.

A variety of geometries, as detailed in Section 2.2, were then designed and constructed using GAMBIT. Each geometry was designed with a length of $1 \mathrm{~m}$, to facilitate comparisons among the geometries. The geometries were constructed and meshed using GAMBIT, with a mesh size of $1 \mathrm{~mm}$ in the region of the insert and $2 \mathrm{~mm}$ in the rest of the reactor model. This enabled the accurate calculation of flow profiles and particle trajectories once the geometry was exported to FLUENT.

\subsection{Simulation of flow in FLUENT}

FLUENT 6.3.26 was the Computational Fluid Dynamics (CFD) software used in the modeling of flow in the reactor system. The standard k- $\varepsilon$ turbulence model (19) was used in all simulations. Each mesh was input into FLUENT and after the grid had been checked and scaled, grid interfaces were defined and water-liquid was selected from the FLUENT database of materials. Operating and boundary conditions were then inputted as follows:

\section{Operating Conditions}

$$
\begin{aligned}
& \text { Gravity }=-9.814 \mathrm{~m}^{2} / \mathrm{s}(\mathrm{y} \text {-direction }) \\
& \text { Pressure }=101,325 \mathrm{~Pa} \text { (atmospheric) } \\
& \text { Temperature }=25^{\circ} \mathrm{C}
\end{aligned}
$$

\section{Boundary conditions}

Velocity inlet: The inflow was chosen to be the top right of the two-pipe model (as water flows from top to bottom in the full-scale CPC), meaning that the inlet velocity was inputted as a negative number. The flow rate 
was taken from experimental runs on the modeled reactor system and had a value of $9.3 \mathrm{~L} / \mathrm{min}$. The velocity was calculated by dividing the flow rate by the internal cross-sectional area of the tube.

$x$-velocity $=-0.0933 \mathrm{~m} / \mathrm{s}$

The turbulent intensity was calculated from Eqn 4 (20).

$$
I \equiv \frac{u}{u_{\text {ave }}}{ }^{\prime}=0.16\left(\operatorname{Re}_{D_{H}}\right)^{-1 / 8}
$$

where $\mathrm{Re}_{\mathrm{DH}}$ is the Reynolds number of the flow regime.

$$
\operatorname{Re}_{D_{H}}=\frac{\rho \times v \times D_{H}}{\mu}
$$

where $\rho=$ fluid density $\left(1000 \mathrm{~kg} / \mathrm{m}^{3}\right) ; v=$ velocity of flow $=0.093 \mathrm{~m} / \mathrm{s} ; D_{H}=$ hydraulic diameter (see Equation 7) and $\mu=$ fluid viscosity $=8.9 \times 10^{-4} \mathrm{~Pa}$ s for water at $25^{\circ} \mathrm{C}$.

The hydraulic diameter is calculated from the following equation:

$$
D_{H}=\frac{4 A}{p}
$$

where $A$ is the internal cross sectional area of the pipe and $p$ is the wetted perimeter. From this,

$$
D_{H}=\frac{4 A}{p}=\frac{4 \times \pi r^{2}}{2 \pi r}=2 r=D
$$

Hydraulic diameter $=0.046 \mathrm{~m}$, which, when substituted into Eqn. 6, gives a Reynolds number of 4821, indicating turbulent flow. The turbulent intensity, calculated from Eqn. 5, is, therefore, $5.54 \%$, again a value associated with turbulent flow.

Outflow: The outflow was set as a pressure-outlet and was situated at the bottom right of the two-pipe model. Again the turbulent intensity and hydraulic diameter were set at $5.54 \%$ and $0.046 \mathrm{~m}$, respectively.

Fluid: The fluid was set as the previously selected water-liquid.

The model was then initialized and iterated until convergence. The relative residuals were selected as $1 \times 10^{-4}$ to ensure good convergence would be achieved. The velocity and turbulence intensity profiles were checked and contours of these parameters were displayed. A discrete phase model was then implemented, as detailed in Section 2.5 below.

\subsection{Particle tracking in FLUENT}

FLUENT allows the user to model a discrete second phase, consisting of solid particles (which can be used to represent bacteria), in a Lagrangian frame of reference. The programme is capable of computing the trajectories of these particles and can predict the effects of turbulence on them. For the discrete phase model, E. coli was set as a user-defined material, with density $1100 \mathrm{~kg} / \mathrm{m}^{3}(21)$, and diameter $1 \times 10^{-6} \mathrm{~m}$ [as measured under an electron microscope (Jeol 2100) in the university facilities]. 
A surface injection was chosen, whereby one particle was released from each mesh area on the inflow surface, giving 406 particles in total. The 'Interaction with continuous phase' setting was chosen, which enabled a coupled calculation of the discrete and continuous phases. For the discrete phase model, the boundary conditions of the irradiated surface area were set to 'trap'. This meant that any particle coming into contact with the insert would be reported in the console window as 'trapped', thus allowing the quantification of $E$. coli interaction with the irradiated area of each geometry.

\section{Results and Discussion}

It should be noted that the number of bacteria coming into contact with each insert will be approximately in proportion to the disinfection efficiency. It has been reported previously that hydroxyl radicals have a very short lifetime (22) and therefore photocatalytic disinfection is effectively a surface phenomenon. The results of particle tracks are summarized in Table 1.

\subsection{No insert}

The model run without an insert, with a $1 \mathrm{~m}$ section of pipe set as the irradiated area, exhibited the poorest performance in terms of particle hits, with none of the tracked particles coming into contact with the area under question, the $1 \mathrm{~m}$ length of the interior of the glass tube. The high degree of turbulence created as the fluid moved around the bend dissipated relatively quickly and did not promote a high degree of mixing in the reactor tube.

\subsection{Cylinders}

For the cylindrical insert, the attenuation of the intensity of radiation reaching the insert surface can be calculated relatively simply from the Beer-Lambert Law (Eqn. 4):

$$
I(z)=I_{0} e^{-k_{e}\left(r_{t}-r_{i}\right)}
$$

where $r_{t}$ is the internal radius of the reactor tube and $r_{i}$ is the radius of the cylindrical insert. Note: $I_{0}$ here refers to the intensity of light at the internal surface of the reactor tube. Typical values of $k_{e}$ presented in literature have ranged from $0.03 \mathrm{~m}^{-1}$ in pure water to $4 \mathrm{~m}^{-1}$ in highly colored lakes (23). Even for the smallest insert radius (10 $\mathrm{mm}$ ) at an extremely conservative extinction coefficient of $4 \mathrm{~m}^{-1}$, the intensity reaching the catalyst is only reduced by $0.92 \%$, meaning this effect is negligible due to the small diameter of the tubing.

The optically idealized cylinder (Model 2) trapped $8.9 \%$ of particles flowing around it, which would seem to confirm that a fixed catalyst on such a cylinder would yield better photocatalytic disinfection than a coated tube. This value can also be used to compare the efficiencies obtained for the different insert geometries modeled, as discussed below.

The cylinder with radius $10 \mathrm{~mm}$ (Model 3) showed the worst insert performance in terms of particles coming into contact with the irradiated surface area $(2.7 \%)$. Whereas turbulence would be expected to be quite high due to the low velocity in the region of the insert, it was found that turbulence increased with insert size. This effect is due to the sudden constriction of the flow and the edge losses as the flow comes into the insert region. The irradiation received by the $10 \mathrm{~mm}$ radius cylindrical insert would also be lower than for the $17.29 \mathrm{~mm}$, as the refractive index of water affects the concentration factor according to Eqn. 2.

When the radius was raised to $15 \mathrm{~mm}$ (Model 4), the number of particles striking the irradiated surface increased, which would be expected from the limited cross-sectional area through which the particles were able to flow. As mentioned above, the turbulence also increased due to the sudden constriction of flow. 
Finally, when a radius of $20 \mathrm{~mm}$ was used (Model 5), creating an average fluid velocity of $0.38 \mathrm{~m} / \mathrm{s}$ around the insert, $13.4 \%$ of particles came into contact with the hypothetical $\mathrm{TiO}_{2}$ sites, although it should be noted that the residence time for the particles in the $1 \mathrm{~m}$ section was relatively low. Research by Sichel et al. (19) showed that increased flow rate was seen to have a negative impact on disinfection rates with respect to UV dose in fixed photocatalysis, a phenomenon that was even more pronounced when disinfection in dark experiments was taken into account. The authors attributed the effect to better interaction between cells and catalyst particles at slower flow rates. Thus, the influence of the synergistic effect of flow rate and number of particles contacting the irradiated area needs further investigation in an experimental comparison of the inserts designed. As the light intensity and concentration factor would not show significant variation between the $20 \mathrm{~mm}$ and $17.29 \mathrm{~mm}$ inserts, it could be concluded that for photocatalytic applications, increasing the insert radius could improve photocatalytic disinfection rates.

\subsection{Frusta}

For the frusta, an integration must be carried out to determine the average intensity of solar radiation. The variation in cross-sectional area as well as the depth variation along the length of the frustum needs to be considered. In this case, the integration along the length of the frustum can be expressed as:

$\bar{I}=\frac{\int_{0}^{L} I_{0} e^{-k_{e}\left\{r_{i}-\left[r_{1}+\left(r_{2}-r_{1}\right) l / L\right]\right\}} x 2 \pi\left(r_{1}+\left(r_{2}-r_{1}\right) l / L\right)}{A} \cdot d l$

(Eqn. 10)

where $r_{1}$ is the minor frustum radius, $r_{2}$ is the major frustum radius, $L$ is the perpendicular length of the frustum and $\mathrm{A}$ is the frustum area, which can be obtained from:

$$
A=\pi\left(r_{1}+r_{2}\right) s
$$

Here, $\mathrm{s}$ is the slant height, easily obtained from Pythagoras's theorem:

$$
s=\sqrt{h^{2}+\left(r_{1}-r_{2}\right)^{2}}
$$

Eqn. 10, upon integration, gives

$$
\bar{I}=\frac{2 \pi I_{0} L e^{-k_{e} r_{t}+k_{e} r_{1}}}{A k_{e}}\left[\left(\frac{r_{1} L}{r_{2}-r_{1}}+L-\frac{L}{k_{e}\left(r_{2}-r\right)}\right) e^{\frac{k_{e}\left(r_{2}-r_{1}\right) l}{L}}\right]_{0}^{L}
$$

Inputting the same $k_{e}$ value of $0.5 \mathrm{~m}^{-1}$ again shows negligible light attenuation within the fluid, with less than 0.3 $\%$ attenuation in both frustum models.

The frustum with minor radius $16.29 \mathrm{~mm}$ and major radius $18.29 \mathrm{~mm}$ (Model 6) displayed better performance in terms of particle hits $(10.5 \%)$ than the cylinder with radius $17.29(8.9 \%)$, despite having almost identical volume and irradiated surface area. In the case of the frustum, as the cross-sectional area of flow available to the particles gradually decreases along the length of the frustum, they are more likely to come into contact with the irradiated area. When the direction of the frustum was reversed in Model 7, the number of particles tracked was almost exactly the same. As can be seen in Figure 4, the turbulent intensity is very high as the flow is constricted when it comes into contact with the insert, promoting more mixing of the fluid and encouraging cells to come into contact with the insert. However, as the insert radius then decreases in the direction of flow, the cells will move in the $\mathrm{x}$-direction and the shape of the insert is then not conducive to contact with the particles. 
When the dimensions of the frustum were changed to a minor radius of $14.29 \mathrm{~mm}$ and a major radius of 20.29 $\mathrm{mm}$ (Model 8), the performance in terms of number of particles trapped by the geometry increased dramatically (31\%). As can be seen in Table 1, the irradiated area and volume were only slightly larger than that of the previous frustum examined and the cylinder with radius $17.29 \mathrm{~mm}$ (and hence the residence time along the insert is only slightly smaller). This means that the much higher number of particles trapped is due to the difference in shape, rather than size, of the inserts. Any particles travelling in the x-direction will tend to be caught if they do not deviate, or only deviate slightly from flow in the x-direction. As the flow becomes more and more constricted along the length of the insert (Figure 5), turbulence will increase, promoting more contact between cells and the insert wall. Hence, this frustum shape could be developed as a possible alternative to the more conventional cylinders used as supports for fixed photocatalysts in CPC reactors.

When this frustum is reversed (Model 9), the high degree of turbulence caused by the significant sudden constriction of the flow (Figure 6) is negated by the tapering of the insert in the direction of flow, which is not conducive to contact with cells travelling in the positive $\mathrm{x}$-direction.

\subsection{Consecutive frusta}

The consecutive frusta models were conceived in order to increase the number of areas of high turbulence along the length of the insert. It also increases the steepness of the slant height for the frusta, $s$ (Eqn. 12), as the radius increases by the same degree as before, but over a shorter perpendicular length $(200 \mathrm{~mm}$, as opposed to 1,000 $\mathrm{mm}$ ). The light attenuation in the water was calculated using Eqn. 13, and again was seen to be negligible. Model 10 showed slightly improved particle hit results $(11.1 \%)$ when compared with the single frustum with the same radii (Model 6,10.5\%). This can be attributed to the increased turbulence at each of the intersections of the five frusta, as well as the steeper profile discussed above. When this multi-frusta arrangement was turned around, so that the radius decreased in the direction of flow (Model 11), there was a slight increase in the number of particle hits $(11.1 \%)$. From Figure 7, it can be seen that the turbulence intensity at the intersections for Model 11 was slightly greater than that for Model 10 . This would appear to outweigh the positive effect on particle hits that would be brought about by the increasing radius in Model 10.

When the dimensions used in Models 8 and 9 were applied to the consecutive frusta (Models $12 \& 13$ ), the number of particle hits in both cases exceeded those for the respective single frustum profiles. Figure 8 shows that a very high turbulence intensity is created at the frustum intersections. Again, this leads to greater radial variation of particle trajectories and increases the likelihood of cells contacting the irradiated surface. Coupled with the effect of the steeper slope of the irradiated area, this explains why the highest number of particle hits (34\%) was achieved by this design. When the arrangement was reversed (Model 13), the turbulence intensity was extremely high again, but the steep tapering of the insert radius in the direction of flow explains the less effective performance $(17.4 \%)$ in relation to Model 12. One factor to be considered in these frustum-shaped designs is whether biofilms accumulate at the intersection of adjacent frusta.

\subsection{Spring}

Whereas the spring was the geometry that gave the highest particle residence time in the $1 \mathrm{~m}$ section of the reactor tube and encouraged a degree of turbulence, its major disadvantage was that most of the flow was directed through the centre of the helix [Figure 9 (a)]. Here, target organisms would be shaded to some degree by the insert and would not receive optimum intensities for solar disinfection due to the diminished concentration factor. In this case, the irradiated area included the tube area on the inside of the helix, where the attenuation due to the Beer-Lambert Law (Eqn. 4) would be slightly higher, although still negligible for practical purposes, with a maximum value of $1.9 \%$. The losses due to refraction would be greater, however, and further research is required to investigate the effects of this. The mixing of the fluid can be seen in the sample particle track displayed in Figure 9 (b). The $11.3 \%$ of particles striking the insert is an encouraging return for an insert with such a small volume, but the concentration of the flow through the centre imposes limitations on this design as discussed. 
In Model 15, the cylinder with radius $17.29 \mathrm{~mm}$ was embedded in the spring from Model 14, in order to investigate whether the mixing promoted by the spring would influence the number of particle hits. This effect was observed to some extent, with $9.8 \%$ of particles trapped as opposed to $8.9 \%$ without the spring. The improvement may have been more significant had the spring been expanded, such that the cylinder was completely inscribed.

\subsection{Optimum design and limitations of CFD modeling}

A geometry recommended for further modeling is an arrangement of consecutive frusta, in which the first frustum decreases in radius in the direction of flow and the subsequent frusta have radii which increase in the direction of flow. That is, the first frustum in Model 12 would be turned around, with the others remaining as they are, as shown in Figure 10. This would combine the turbulence properties found at the frustum intersections and favorable shape seen in Model 12 with the turbulence due to sudden constriction of flow at the start of the insert region, seen in Model 13. This turbulence at the beginning of the insert region implies that a significant number of particle hits will occur at that point. Therefore, it might be preferable for the insert to be positioned such that there is a short initial flow period in the irradiated reactor tube before the insert is met. This could be a more effective alternative to a lot of current designs where the insert support spans the length of the irradiated tube. However, fixed inserts have to be held in place in the centre of the reactor tube, so structures for achieving this would have to be considered in further designs.

The CFD modeling regime undertaken provides an interesting comparison of the efficiency of supports of different shapes. It does, however, need to be followed up with a regime of experiments on the inserts in order to investigate the influence of a number of factors not incorporated into the modeling, namely:

- catalyst sloughing

- the accumulation of biofilms on inserts and hence the reusability of inserts

- the most effective support materials

- cell/catalyst surface charge effects

- the effect of concentration factor variation as a result of different support geometries

\section{Conclusions}

The modelling of the fluid dynamics of particles in tubular reactors with different inserts has shown that as cylinder radius increased, the number of particles coming into contact with the inserts increased, which would be expected due to the limited cross-sectional area available for flow. It must be determined from experiments whether the relationship between the number of particle hits and residence time in the vicinity of the insert can be optimized with respect to the reaction process being designed - whether the particles be bacteria in a disinfection reactor or pollutants in a detoxification reactor for example.

Whereas frusta displayed favorable characteristics in general over cylindrical inserts, the combination of frusta to create what could be described as a 'Christmas tree' shape, showed the most encouraging results in terms of the numbers of particles coming into contact with the irradiated area. This has interesting implications for the future design of fixed photocatalytic supports for photoreactors, as optical losses due to the change in shape are minimal, as are changes in particle residence times in the insert region.

Clearly, modeling alone is insufficient to determine the exact disinfection capabilities of a particular insert geometry. Therefore further research is needed whereby full-scale controlled experimental analyses of these inserts are carried out using an indicator organism such as $E$. coli and compared against the relative disinfection efficiencies simulated in this paper. The modeling carried out utilized a relatively simplistic approach, with a relatively low number of particles considered, no investigation of cell/catalyst surface charge effects and simplified incident solar intensity assumptions. However, the comparative efficiencies of the various inserts 
provide interesting possibilities for future fixed photocatalytic designs as it is hoped that the results seen in this paper can be correlated with real disinfection kinetics.

\section{Acknowledgments}

The work presented in this paper was conducted with the financial assistance of the Irish Research Council for Science, Engineering and Technology (IRCSET).

\section{References}

(1) MATSUnAGA, T., TOMODA, R., NAKAJIMA, T. \& WAKE, H. (1985) Photoelectrochemical sterilization of microbial cells by semiconductor powders. FEMS Microbiology Letters, 29, 211-214.

(2) MCloughlin, O. A., IBÁÑEZ, P. F., GERNJAK, W., RODRIGUEZ, S. M. \& GILL, L. W. (2004a) Photocatalytic disinfection of water using low cost compound parabolic collectors. Solar Energy, 77, 625633.

(3) FERNÁNDEZ, P., BLANCO, J., SICHEL, C. \& MALATO, S. (2005) Water disinfection by solar photocatalysis using compound parabolic collectors. Catalysis Today, 101, 345-352.

(4) RINCON, A.-G. \& PULGARIN, C. (2007b) Fe3+ and TiO2 solar-light-assisted inactivation of E. coli at field scale: Implications in solar disinfection at low temperature of large quantities of water. Catalysis Today, $122,128-136$.

(5) GOMES, A. I., SANTOS, J. C., VILAR, V. J. P. \& BOAVENTURA, R. A. R. (2009) Inactivation of Bacteria E. coli and photodegradation of humic acids using natural sunlight. Applied Catalysis B: Environmental, 88, 283-291.

(6) MALATO RODRÍGUEZ, S., BLANCO GÁlVEZ, J., MALDONADO RUBIO, M. I., FERNÁNDEZ IBÁÑEZ, P., ALARCÓN PADILlA, D., COLLARES PEREIRA, M., FARINHA MENDES, J. \& CORREIA DE OLIVEIRA, J. (2004) Engineering of solar photocatalytic collectors. Solar Energy, 77, 513-524.

(7) NAVNTOFT, C., UBOMBA-JASWA, E., MCGUiGAN, K. G. \& FERNÁNDEZ-IBÁÑEZ, P. (2008) Effectiveness of solar disinfection using batch reactors with non-imaging aluminium reflectors under real conditions: Natural well-water and solar light. Journal of Photochemistry and Photobiology B: Biology, 93, 155-161.

(8) ALFANO, O.M., BAHNEMANN, (2000) Photocatalysis in water
D., CASSANO, environments
A.E., DILLERT,

R., GOSLICH, R. Catalysis Today, 58(2), 199-230

using artificial and solar light.

(9) FERNÁNDEZ-IBAÑEZ, P., BLANCO, J., MALATO, S. (2003) Application of the colloidal stability of $\mathrm{TiO}_{2}$ particles for recovery and reuse in solar photocatalysis. Water Research, 37, 3180-3188.

(10) BIDEAU, M., ClAUDEL, B., DUBIEN, C., FAURE, L. \& KAZOUAN, H. (1995) On the "immobilization" of titanium dioxide in the photocatalytic oxidation of spent waters. Journal of Photochemistry and Photobiology A: Chemistry, 91, 137-144.

(11) RINCON, A. G. \& PULGARIN, C. (2003) Photocatalytical inactivation of E. coli: effect of (continuousintermittent) light intensity and of (suspended-fixed) $\mathrm{TiO} 2$ concentration. Applied Catalysis B: 
Environmental, 44, 263-284.

(12) BLANCO-GALVEZ, J., FERNANDEZ-IBANEZ, P., MALATO-RODIGUEZ， S. (2007) Solar photocatalytic detoxification and disinfection of water: recent overview. Journal of Solar Energy Engineering, 129(1), 4-15.

(13) IRELAND, J.C., KLOSTERMANN, P., RICE, E.W., CLARK, R.M. (1993) Inactivation of Escherichia coli by titanium dioxide photocatalytic oxidation. Journal of Applied Environmental Microbiology, 59(5), 1668-1670.

(14) VIDAL, A., DÍAZ, A.I., EL HRAIKI, A., ROMERO, M., MUGURUZA, I., SENHAJI, F., GONZÁLEZ, J. (1999) Solar photocatalysis for detoxification and disinfection of contaminated water: Pilot plant studies Catalysis Today, 54, 283-290.

(15) NAVNTOFT, C., LITTER, M.I., PAUlA ARAUJO, P., APELlA, M.C., FERNÁNDEZ, D., PUCHULU, M.E., HIDALGO, M., BLESA, M.A. (2007) Field Tests of the Solar Water Detoxification SOLWATER Reactor in Los Pereyra, Tucumán, Argentina. Journal of Solar Energy Engineering, 129(1), 127-134.

(16) ELYASI, S., TAGHIPOUR, F. (2006) Simulation of UV photoreactor for water disinfection in Eulerian framework. Chemical Engineering Science, 61(14), 4741-4749.

(17) LIU, D., WU, C., LINDE, K. \& DUCOSTE J. (2007) Numerical simulation of UV disinfection reactors: Evaluation of alternative turbulence models. Applied Mathematical Modeling, 31(9), 1753-1769.

(18) GUILlARD, C., BUI, T.-H., FELIX, C., MOULES, V., LINA, B. \& LEJEUNE, P. (2008) Microbiological disinfection of water and air by photocatalysis. Comptes Rendus Chimie, 11, 107-113.

LAUNDER, B.E., REECE, G.J. \& RODI W. (1975). Progress in the development of Reynolds stress turbulence closure. Journal of Fluid Mechanics, 68, 537-566.

(19) SICHEL, C., BLANCO, J., MALATO, S. \& FERNÁNDEZ-IBÁÑEZ, P. (2007a) Effects of experimental conditions on E. coli survival during solar photocatalytic water disinfection. Journal of Photochemistry and Photobiology A: Chemistry, 189, 239-246.

(20) FLUENT (2006) FLUENT 6.3.2.6 User Guide, Fluent Inc.

(21) BALDWIN, W.W., MYER, R., KUNG, T., ANDERSON, E., KOCH, A.L. (1995) Growth and buoyant density of Escherichia coli at very low osmolarities. Journal of Bacteriology, 177(1), 235-237.

(22) BLAKE, D. M., MANESS, P.-C., HUANG, Z., WOLFRUM, E. J., HUANG, J. \& JACOBY, W. A. (1999) Application of the Photocatalytic Chemistry of Titanium Dioxide to Disinfection and the Killing of Cancer Cells. Separation \& Purification Reviews, 28, 1 - 50.

(23) MARTIN, J.L., MCCUTCHEON, S.C., SCHOTTMAN, R.W. (1999) Hydrodynamics and transport for water quality modeling, Lewis Publishers, Boca Raton.

BRANDI, R.J., CITRONI, M.A., ALFANO, O.M., CASSANO, A.E. (2003) Absolute quantum yields in photocatalytic slurry reactors. Chemical Engineering Science, 58, 979-985. 
COLINA-MÁRQUEZ, J., MACHUCA-MARTÍNEZ, F., PUMA, G.L. (2010) Radiation absorption and optimization of solar photocatalytic reactors for environmental applications. Environmental Science and Technology, 44, 5112-5120.

\begin{tabular}{|c|c|c|c|c|c|c|c|}
\hline Insert & Shape & $\begin{array}{l}\text { Illuminated } \\
\text { area }\left(\mathrm{cm}^{2}\right)\end{array}$ & $\begin{array}{c}\text { Insert } \\
\text { volume } \\
\left(\mathrm{cm}^{3}\right)\end{array}$ & $\begin{array}{l}\text { Average cell } \\
\text { velocity along } \\
\text { insert }(\mathrm{m} / \mathrm{s})\end{array}$ & $\begin{array}{c}\text { Average } \\
\text { residence time } \\
\text { in insert } \\
\text { section }(\mathrm{s})\end{array}$ & $\begin{array}{c}\% \text { of } \\
\text { particles } \\
\text { trapped by } \\
\text { insert }^{\text {a }}\end{array}$ & Major dimensions $(\mathrm{mm})$ \\
\hline 1 & No insert & 1445.1 & 1661.9 & 0.093 & 10.72 & 0.0 & $(\mathrm{r}=23)$ \\
\hline 2 & Cylinder & 1086.4 & 939.2 & 0.214 & 4.66 & 8.9 & $\mathrm{r}=17.29$ \\
\hline 3 & Cylinder & 628.3 & 314.2 & 0.115 & 8.69 & 2.7 & $r=10$ \\
\hline 4 & Cylinder & 942.5 & 706.9 & 0.162 & 6.16 & 8.7 & $r=15$ \\
\hline 5 & Cylinder & 1256.7 & 1256.6 & 0.382 & 2.61 & 13.4 & $\mathrm{r}=20$ \\
\hline 6 & Frustum & 1086.4 & 940.2 & 0.215 & 4.66 & 10.5 & $\mathrm{r}_{1}=16.29, \mathrm{r}_{2}=18.29$ \\
\hline 7 & Frustum & 1086.4 & 940.2 & 0.215 & 4.66 & 10.1 & $\mathrm{r}_{1}=16.29, \mathrm{r}_{2}=18.29$ \\
\hline 8 & Frustum & 1086.9 & 948.6 & 0.217 & 4.60 & 31.0 & $\mathrm{r}_{1}=14.29, \mathrm{r}_{2}=20.29$ \\
\hline 9 & Frustum & 1086.9 & 948.6 & 0.217 & 4.60 & 17.1 & $\mathrm{r}_{1}=14.29, \mathrm{r}_{2}=20.29$ \\
\hline 10 & $5 \times$ Frustum & 1086.4 & 940.2 & 0.215 & 4.66 & 11.1 & $\mathrm{r}_{1}=16.29, \mathrm{r}_{2}=18.29$ \\
\hline 11 & $5 \times$ Frustum & 1086.4 & 940.2 & 0.215 & 4.66 & 11.9 & $\mathrm{r}_{1}=16.29, \mathrm{r}_{2}=18.29$ \\
\hline 12 & $5 \mathrm{x}$ Frustum & 1086.9 & 948.6 & 0.217 & 4.60 & 34.0 & $\mathrm{r}_{1}=14.29, \mathrm{r}_{2}=20.29$ \\
\hline 13 & $5 \times$ Frustum & 1086.9 & 948.6 & 0.217 & 4.60 & 17.4 & $\mathrm{r}_{1}=14.29, \mathrm{r}_{2}=20.29$ \\
\hline 14 & Spiral & 286.2 & 27.3 & 0.095 & 10.55 & 11.3 & tube $r=2$, helix $r=17.29$ \\
\hline 15 & $\begin{array}{c}\text { Cylinder within } \\
\text { spiral }\end{array}$ & 1092.3 & 953.5 & 0.220 & 4.57 & 9.8 & $\begin{array}{c}\text { tube } r=2 \text {, helix } r=17.29, \\
\text { cylinder } r=17.29\end{array}$ \\
\hline
\end{tabular}

${ }^{\mathrm{a}}$ equivqlent to percentag eof baceria cells coming into conatct with catalyst inserts

Table 1 Summary of insert geometries 
(a)
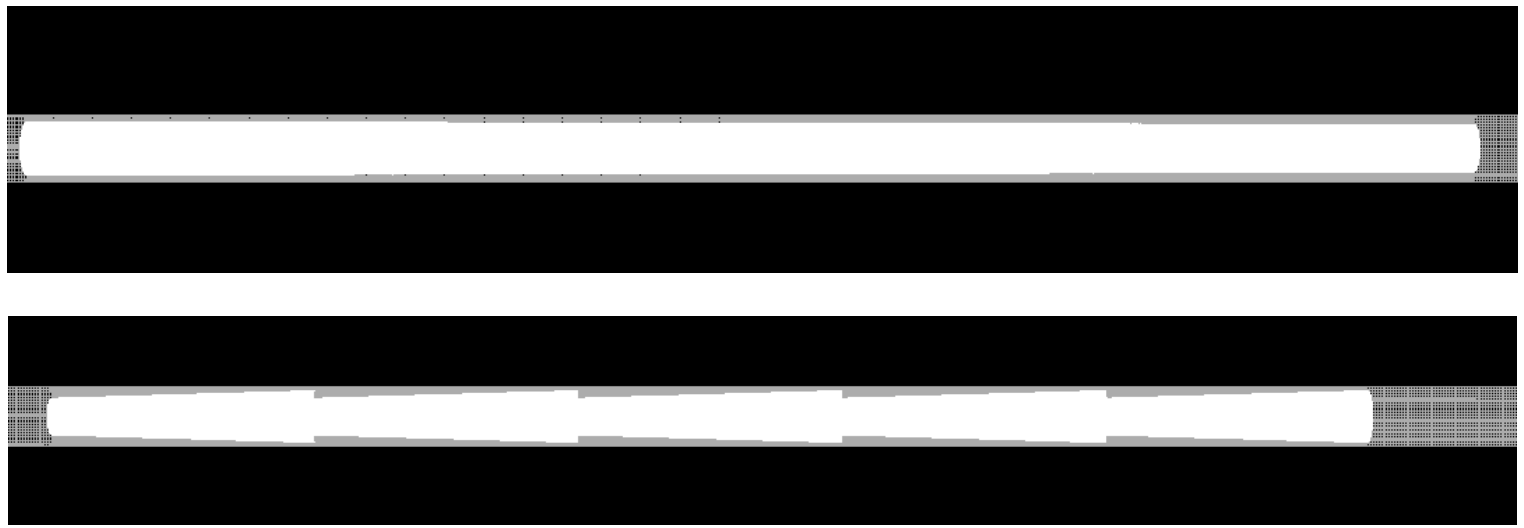

(b)

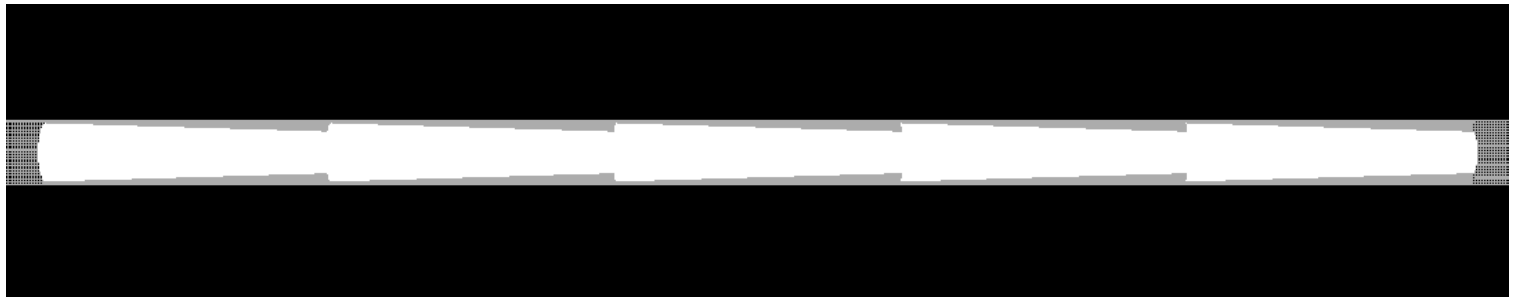

(c)

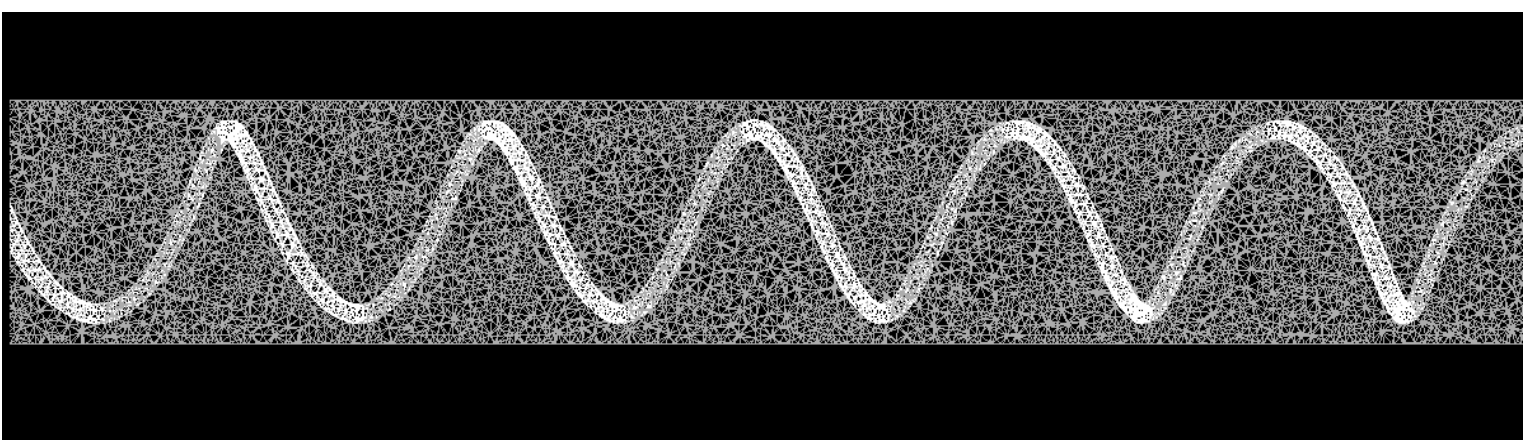

(d)

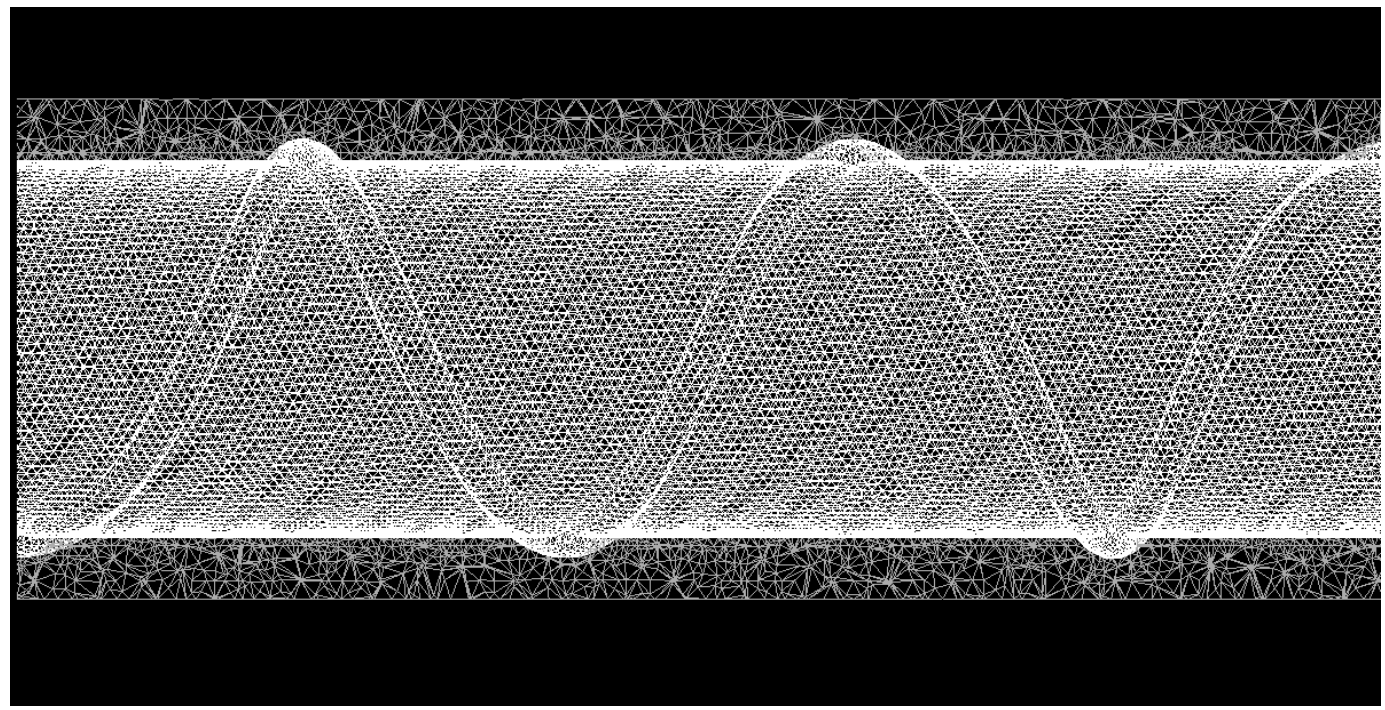

(e)

Figure 1 Examples of insert geometries (a) Frustum (model 7); (b) arrangement of 5 frusta (model 10); (c) arrangement of 5 frusta (model 13); (d) spring (model 14); (e) cylinder merged with spring (model 15). Note: images are magnified and a plane through the reactor along the $\mathrm{z}=0$ plane is drawn in each case to provide scaling. 


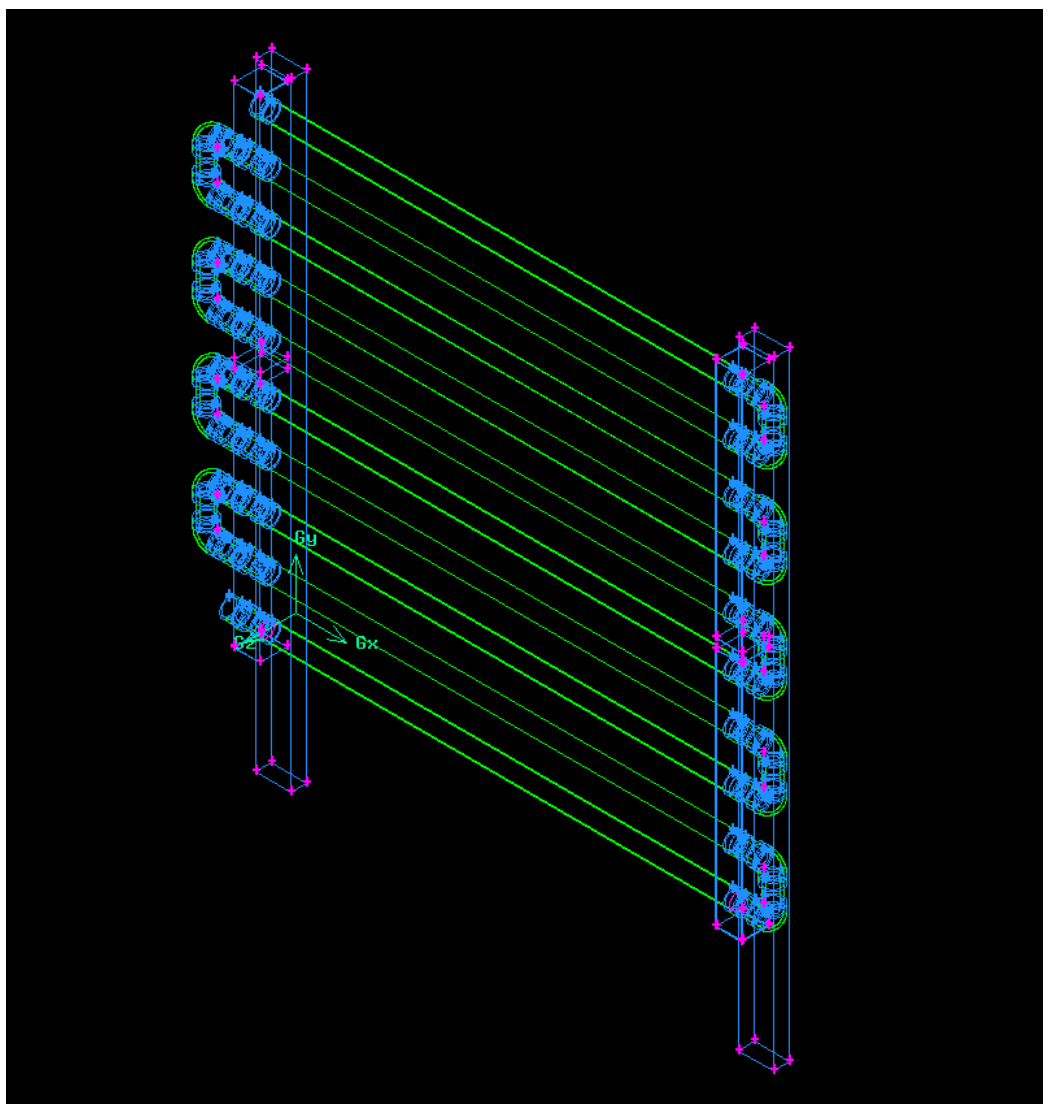

(a)

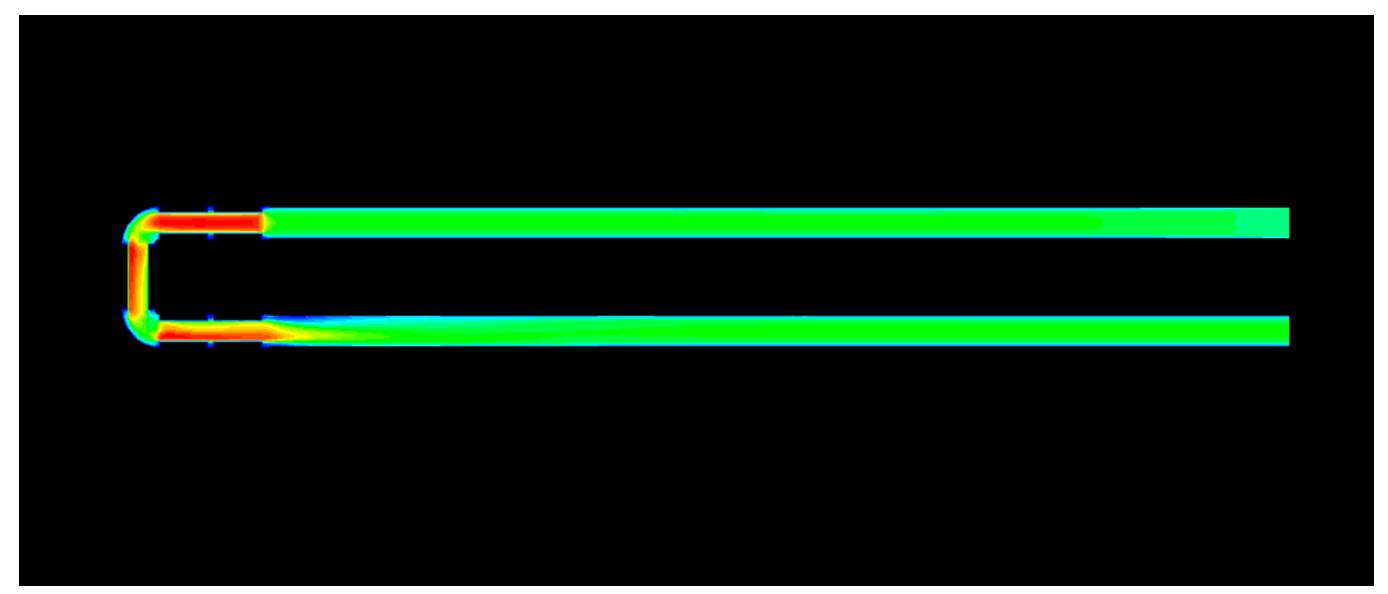

(b)

Figure 2 (a) Technical drawing of the full-scale CPC in GAMBIT; (b) two-pipe section used for modeling purposes. 


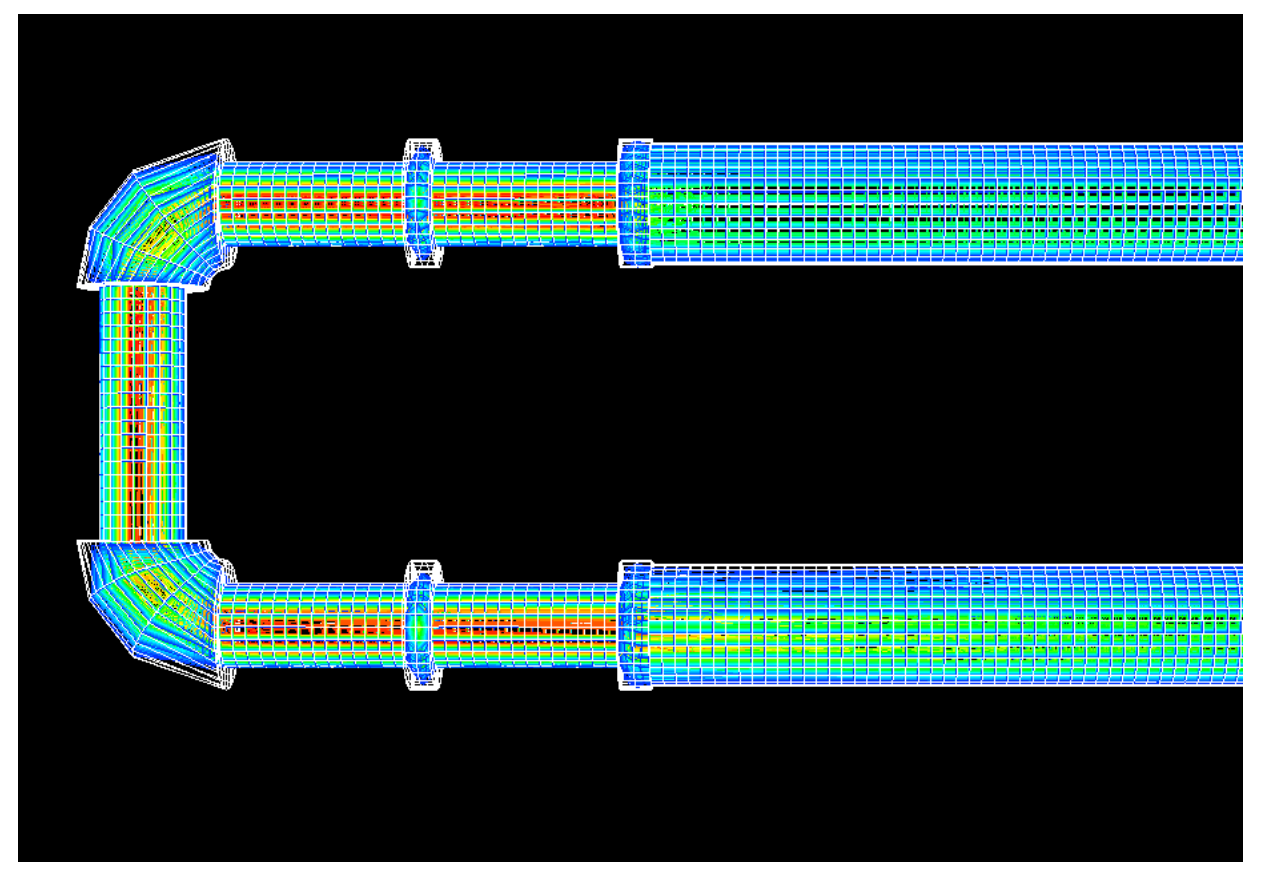

Figure 3 Complex bend connecting pipes

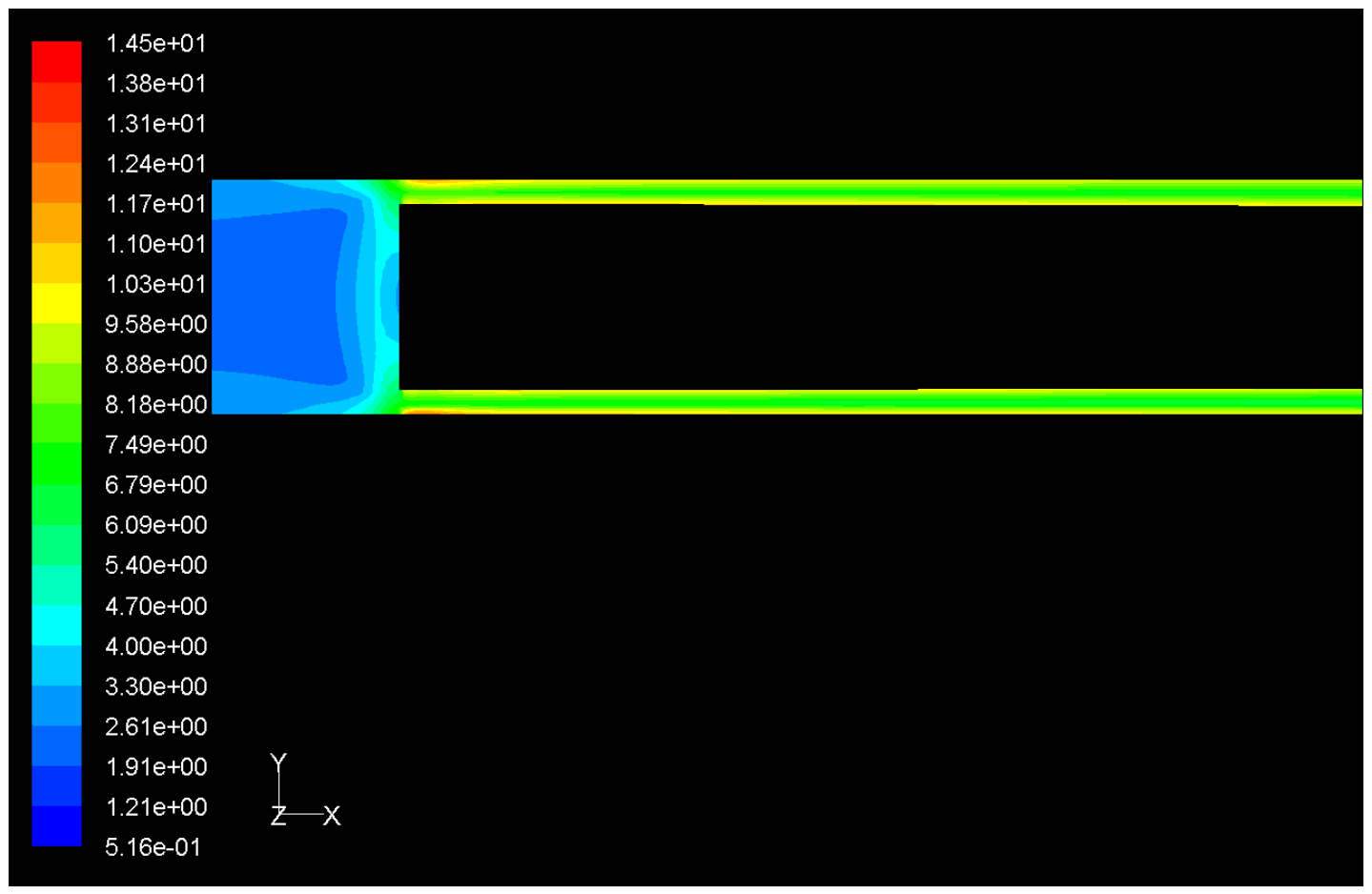

Figure 4 Contours of turbulent intensity $(\%)$ along central plane $(\mathrm{z}=0)$ for Model 7 . The image is a close-up of the section of the pipe where the insert (darkened area) starts. 


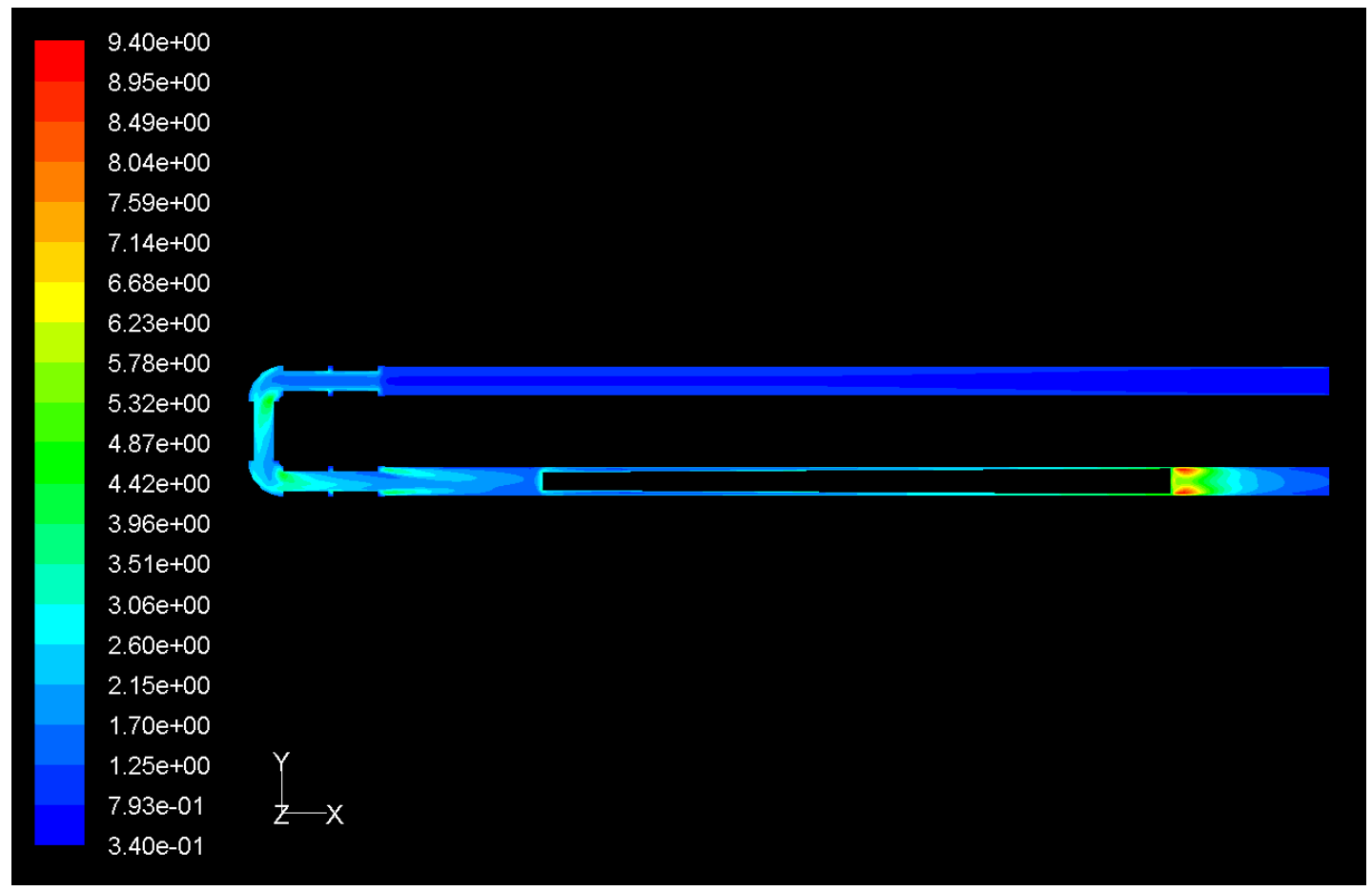

Figure 5 Contours of turbulent intensity $(\%)$ along central plane $(\mathrm{z}=0)$ for Model 8.

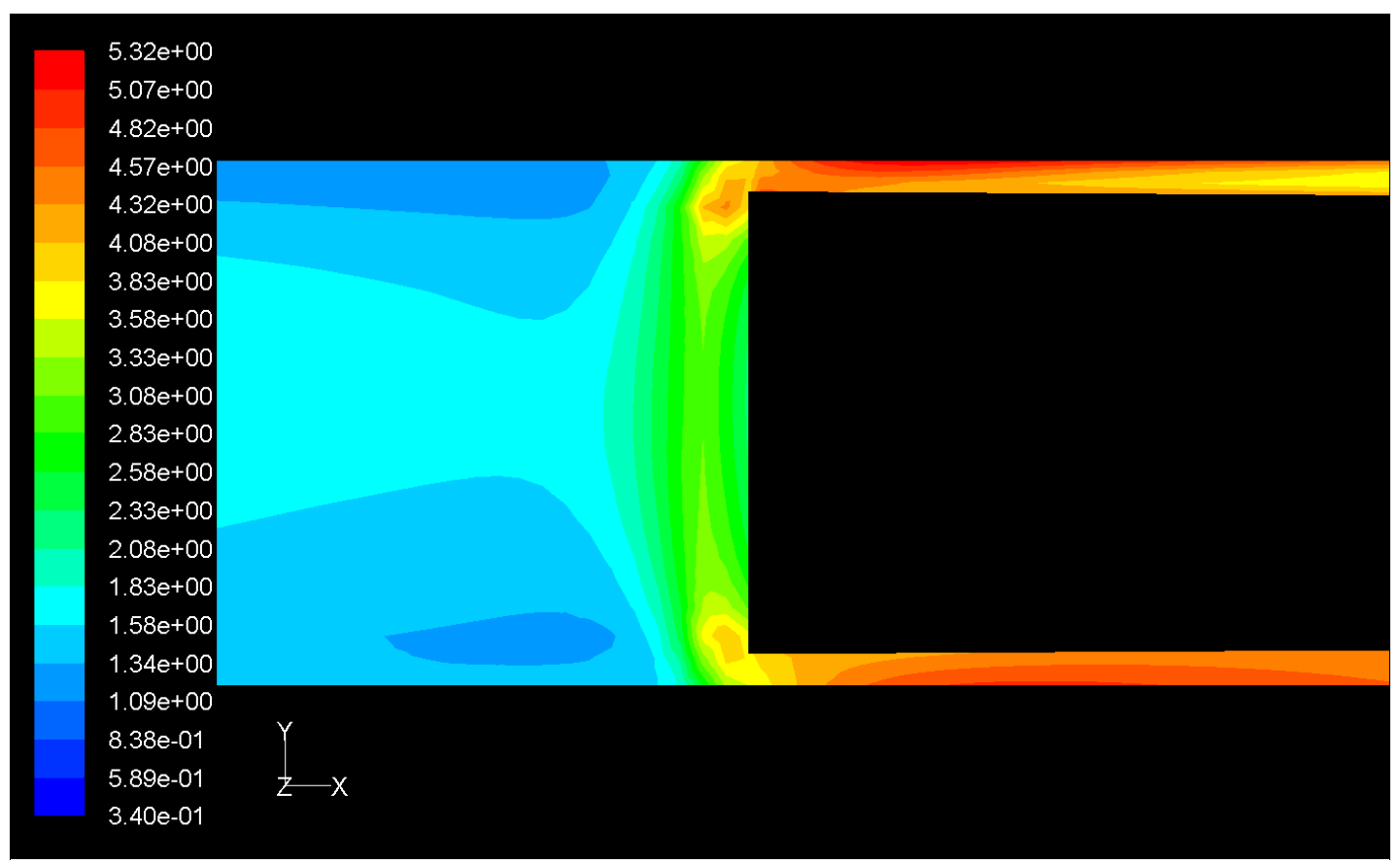

Figure 6 Increase in turbulence intensity (\%) due to flow constriction at the start of the insert (Model 9) 


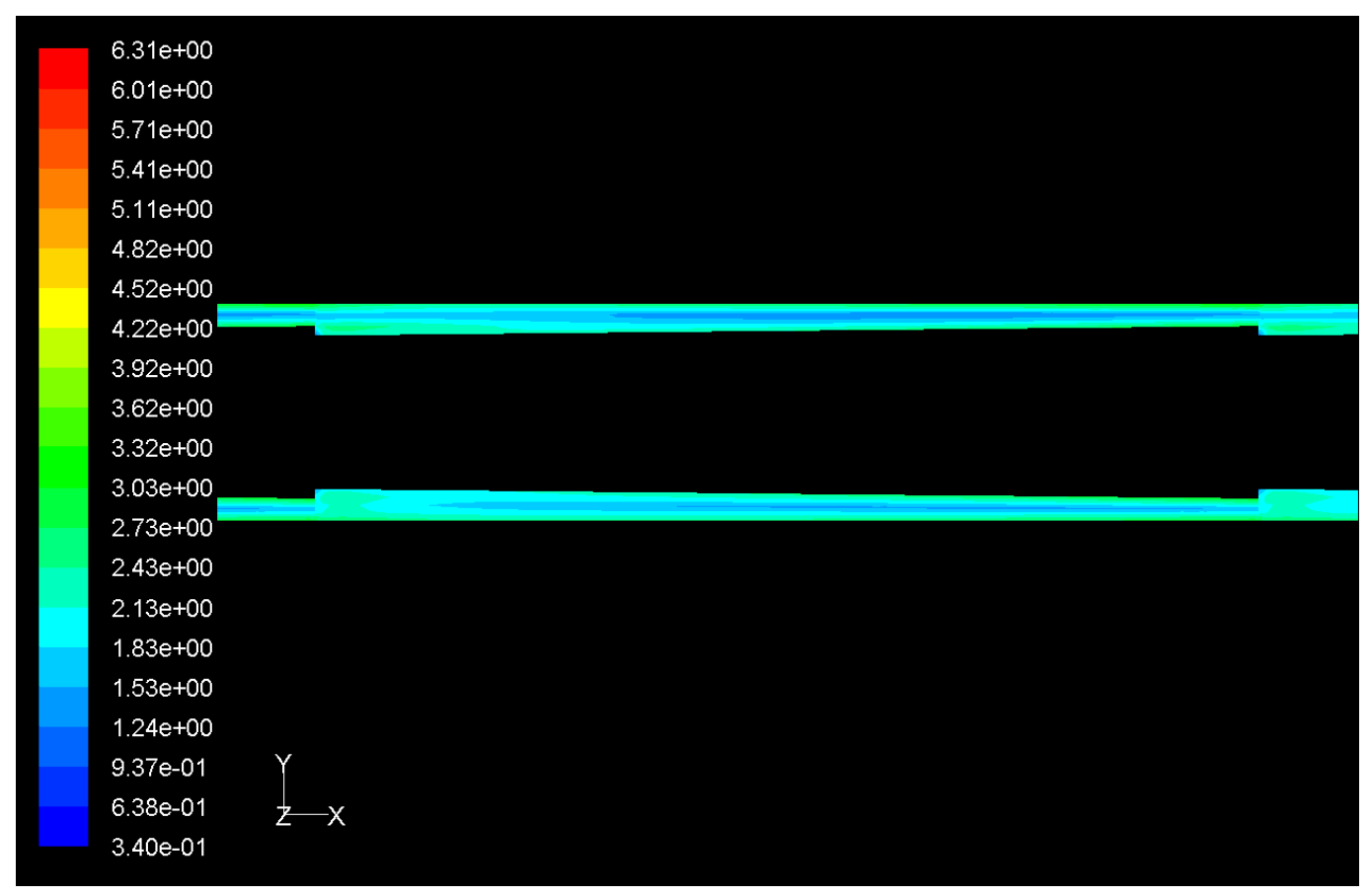

(a)

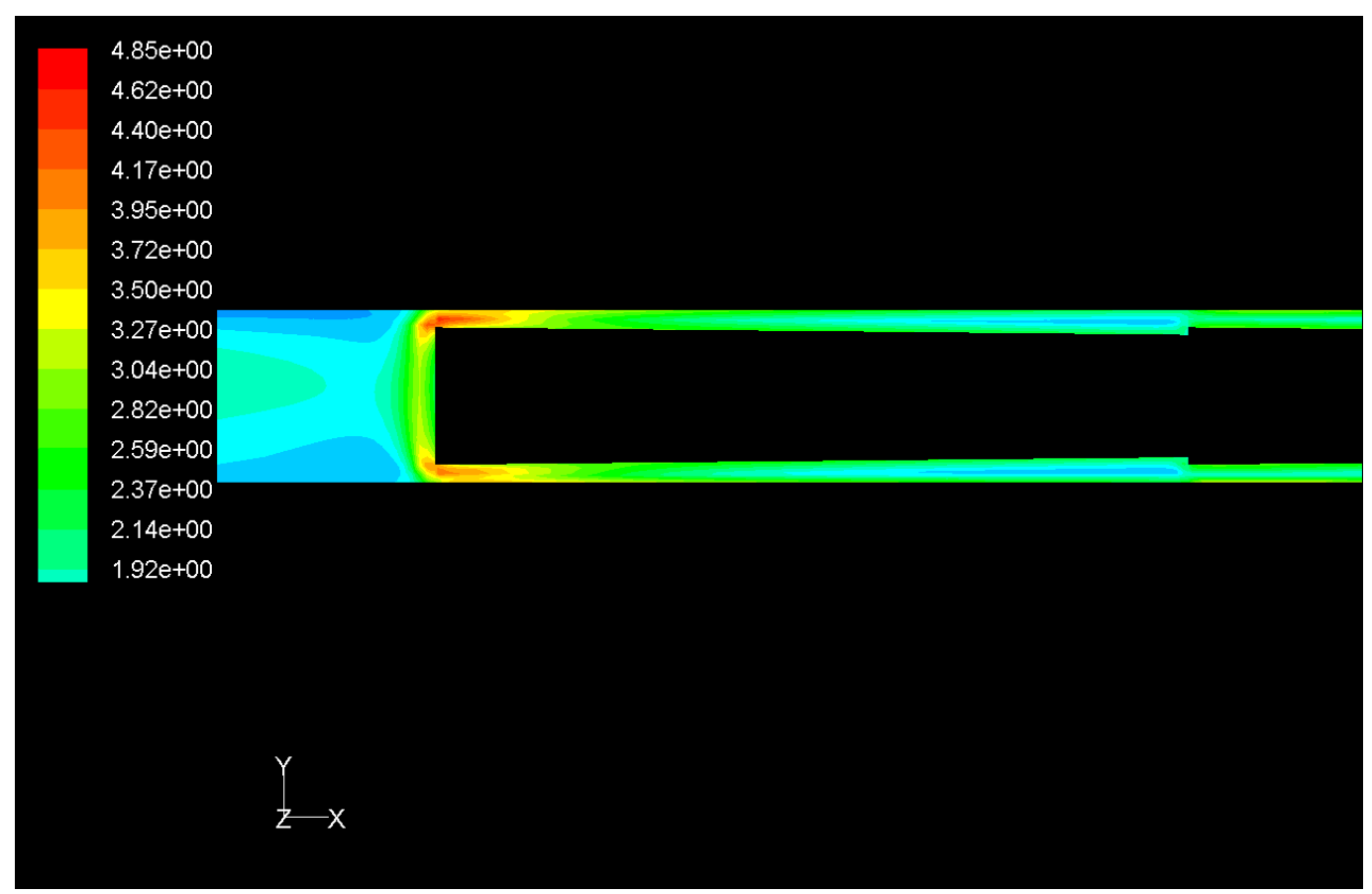

(b)

Figure 7 Turbulence intensity (\%) contours at intersections of frusta; (a) Model 10; (b) Model 11 


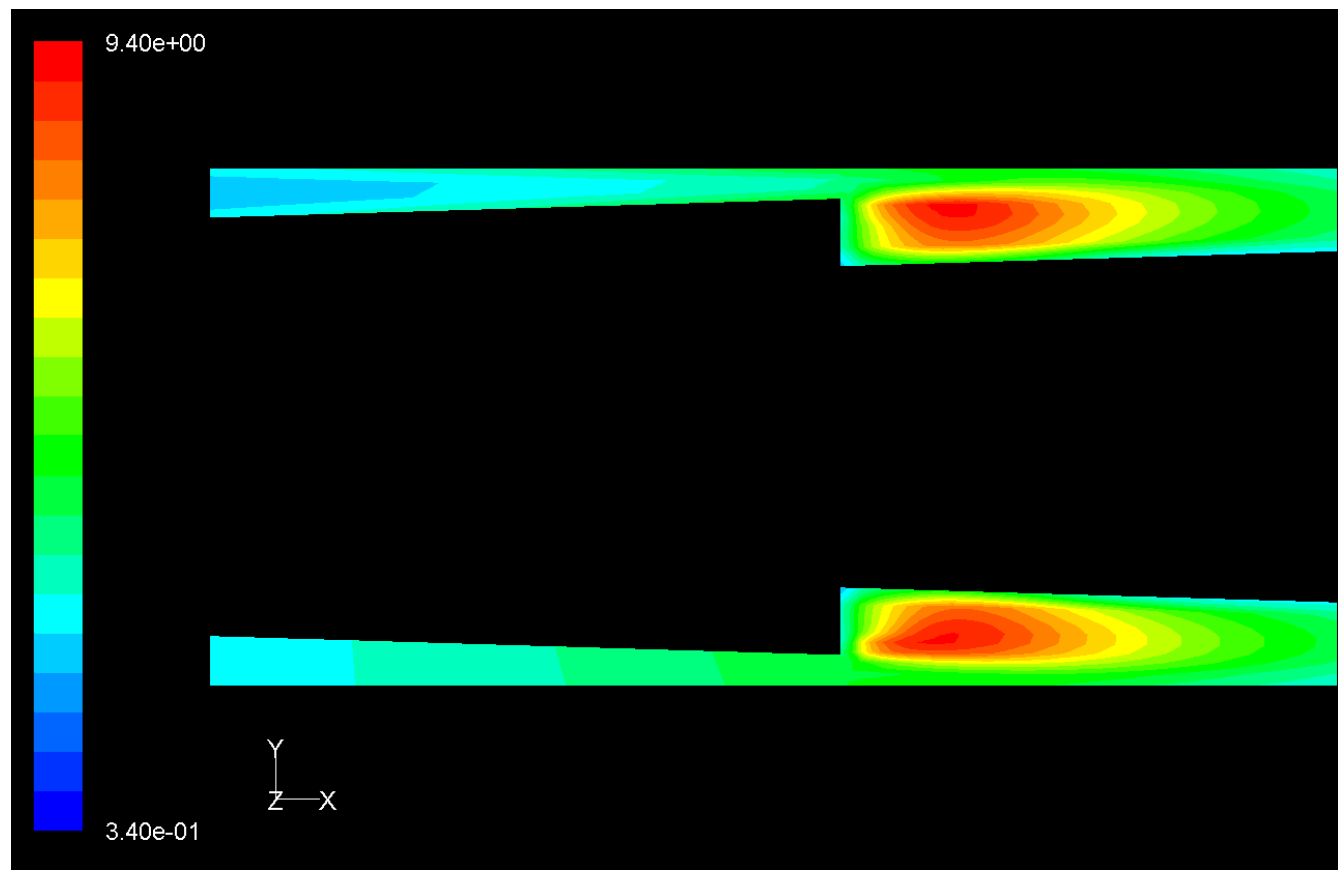

Figure 8 Turbulence intensity (\%) contours for Model 12 


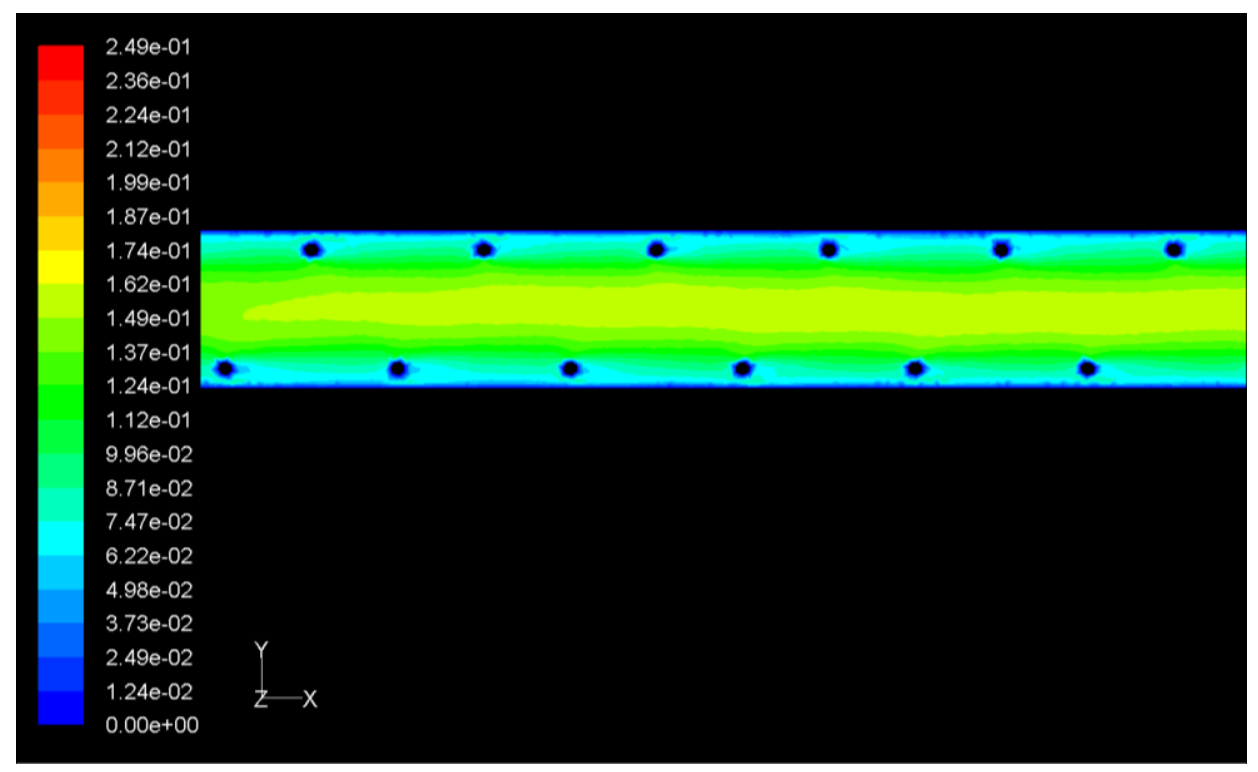

(a)

(b)

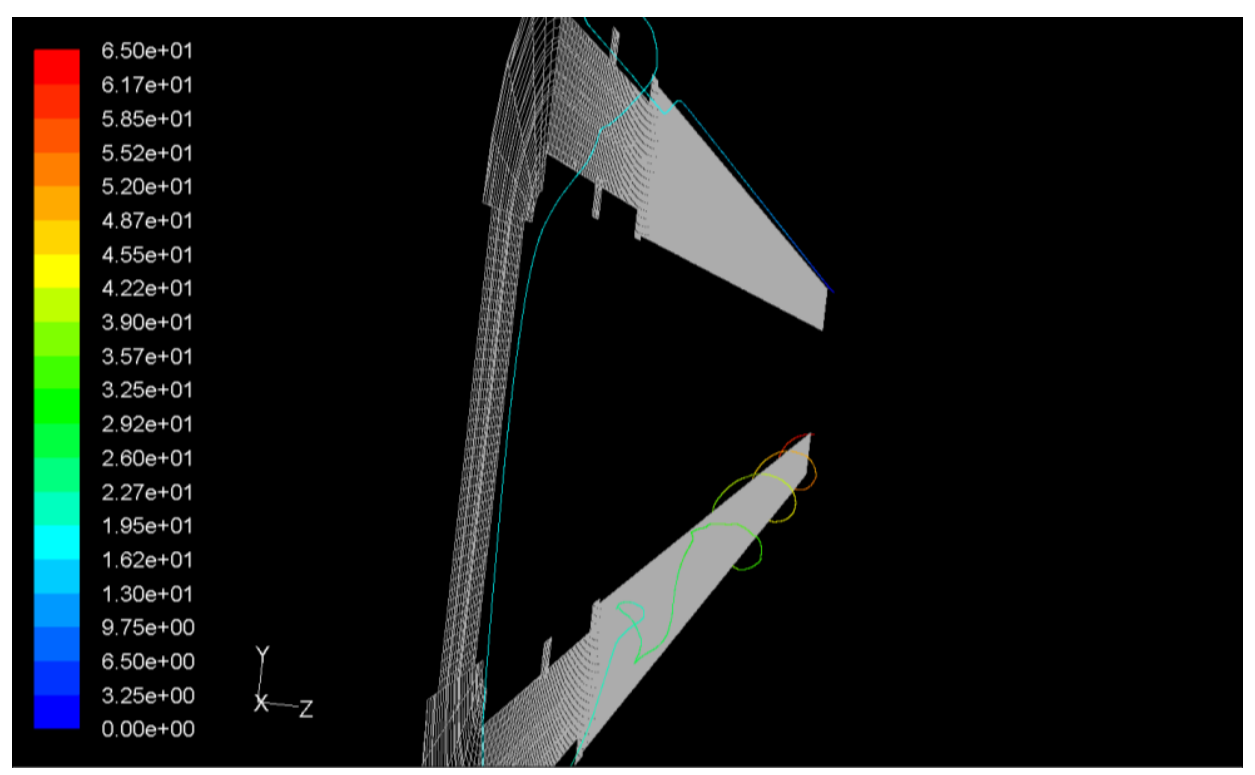

Figure 9 (a) Contours of velocity magnitude (m/s) for Model 14; (b) sample single particle track for Model 14 (again, the $\mathrm{z}=0$ plane is included for context)

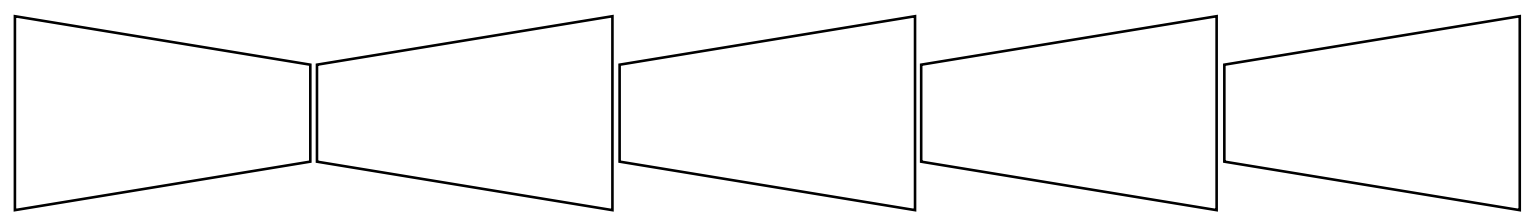

Figure 10 Geometry of possible insert design 